\title{
Summary and Prospects on Theoretical Models and Influencing Factors Research of Employee Creativity
}

\author{
Feng Guo ${ }^{1, *}$ \\ ${ }^{1}$ School of Business, Macau University of Science and Technology, Macau, China \\ *Corresponding author. Email: JeffreyGuoFeng@yeah.net
}

\begin{abstract}
Employee creativity determines the level of innovation and performance of an enterprise organization. Chinese enterprises are facing unprecedented challenges at this stage. Competition in and out of China is becoming increasingly fierce. Each enterprise organization is faced with the severe challenge of how to survive and develop. Choosing to break the situation through innovation first needs to stimulate and enhance the creativity of employees. This article sorts out and reviews the research on employee creativity, summarizes the conceptual definitions, theoretical models, and influencing factors of employee creativity, and puts forward a prospect for the research on employee creativity in the Chinese context.
\end{abstract}

Keywords: Employee creativity, Innovation, Theoretical models, Influencing factors.

\section{INTRODUCTION}

Modern enterprise organizations are in an increasingly uncertain business and political environment, with increasingly fierce competition, and enterprises must strive harder to pursue innovation and creativity than ever before [1]. Employee creativity, that is, generating novel and useful ideas, is described as an important source of organizational competitiveness [2], which is extremely important for the effective survival and development of the organization [3], and is a unique competitiveness factor that is critical to organizational performance [4]. Whether employees are creative determines whether the enterprise has good innovation results, and whether it can continue to survive, develop and grow [5].

\section{DEFINITION OF EMPLOYEE CREATIVITY}

The research on creativity has a long history, and its conceptual definitions are also diverse. So far, there has not yet been an accurate definition that is generally recognized by the academic community. There are roughly three types of definitions with different focus orientations, each focusing on: creativity-related processes, creativityrelated people, and creativity-related results.

The first type of definition mainly focuses on the process of creativity generation or cognition. Researchers analyze creativity from the perspective of process, and regard the process of analyzing and mining the essence of the problem to be solved and the process of generating corresponding solutions related to it as the connotation of creativity. Rogers [6] published an article titled "Towards Creativity Theory" and defined the process of creativity as: the process of producing a novel product, on the one hand derived from the individual uniqueness of its creator, and on the other hand based on the material, event experience, person or environment that its creator has experienced daily; the creativity does not distinguish between good and bad, nor is it affected by failure, let alone the degree of creativity. Busse \& Mansfield [7] believes that creativity is the process of asking questions, conducting investigations and solving problems, paying attention to the stage division of the creative process, and emphasizing the requirements of each stage on the personality characteristics and cognitive abilities of the creative individual. Although the definition of creativity in terms of process can analyze the process of creativity in 
sufficient detail, this definition makes it easier to analyze the process of creativity from a theoretical level. However, empirical research based on this definition will encounter difficulties in quantitative measurement, so it is difficult to continue to study in detail the influence mechanism on creativity by various factors. Therefore, in the follow-up research, there appears the definition of creativity from a personal perspective and a result perspective.

The second type of definition mainly focuses on the individual's ability to generate creative behavior. Guilford [8], then president of the American Psychological Association, gave an inaugural speech entitled "On Creativity", in which he narrowly defined creativity as a kind of ability, a kind of personal ability that is commonly shared by people with outstanding creative behaviors and determines whether an individual can produce a certain degree of creative behavior. This is a personality trait ability defined from a psychological perspective. At the same time, he also focused on the focus of creativity research first on qualitative and quantitative analysis of which specific personality traits are related to creative behavior. Researchers in this field pay attention to the characteristics of creating individuals, and believe that creative individuals have strong curiosity, high levels of internal motivation, high IQ, divergent thinking, and have personality characteristics such as persistence, daring to take risks, and breaking conventions. However, starting from this definition, the objects of research are elites in the population, such as experts, scientists, outstanding contributors, etc., ignoring the participation and contribution of most nonexceptional personnel in creativity-related work. And although most of the subjects studied are highquality people, these people may not necessarily be able to make creative output contributions, which stems from ignoring the effects of contextual factors on creativity.

The third type of definition mainly focuses on the outcome of creative behavior. Amabile [9] summarized previous definitions and came up with a comprehensive definition: creativity refers to a product or result response that is independently observed by multiple effective observers but jointly recognizes its creativity; the effective observers refer to people who are familiar with products in related fields and their production process or result responses; creativity can correspond to novel products or result responses, or it can be a creative manufacturing process. Employee creativity refers to the production of new ideas and new ideas related to product development, service optimization, process improvement, etc., and it is beneficial to the survival and development of enterprises [10]. The novelty and usefulness of an idea are the two core points of its definition. In the follow-up, more and more researchers choose the third definition of creativity, because it focuses on the output of results and can be easily quantified from the perspective of definition. It is especially suitable for application in quantitative empirical research, that is, a definition centered on the outcome of creativity. It more specifically defines creativity as a result output, focusing on creative results such as producing novel and useful ideas. These ideas can be related to products, services, processes, procedures, etc. [1], [5]

Based on the definitions of Amabile and Zhou, this article summarizes employee creativity as: new thoughts, new designs or new ideas related to products, services, work processes, etc. that are beneficial to the survival, operation, competition and development of the company or enterprise created and generated by the employees of a company or enterprise, which are innovative, original, beneficial, and can be used by companies or enterprises in the future to produce practical results.

\section{CREATIVITY AND INNOVATION}

A concept that is closely related to and related to creativity, but has obvious differences, is innovation. In order to avoid ambiguity, this article briefly explains its association and difference: Different from 创造力, which is derived from Creativity in English, the concept of 创新 is derived from the English Innovation, and its conceptual connotation is usually defined as the adoption and execution of new ideas and the realization of their useful value [11]. The concept of creativity, as mentioned above, focuses more on the generation of novel and useful ideas. Innovation is the new ideas generated by creativity are successfully adopted and realized in the organization based on the premise that the new ideas generated by creativity are the results [12]. When innovation is understood as an organic activity that originates from within the organization, rather than an innovative product or service acquired externally, the researchers treat creativity and innovation as different parts of the essentially same process: creativity, is defined as novel and useful ideas generated by the joint efforts of individuals or a small group of people, which are often the front- 
end development of new affairs; and innovation, is defined as the successful introduction, realization and practice of ideas and concepts generated by creativity in an organization [13].

\section{THEORETICAL MODEL OF EMPLOYEE CREATIVITY}

There are various theories or models related to employee creativity, among which the theory of the components of creativity is the most famous and widely used. This article briefly describes the main theories as follows:

\subsection{The Component Model of Employee Creativity}

In response to early related creativity research focusing more on the individual factors of highly creative talents, such as intelligence, personality, etc., while relatively neglecting the impact of innovative thinking ability and other potential external factors on creativity, Amabile [14] proposed a component model of creativity based on psychology. It specifically proposed that creativity has three main components, namely: first, the technical skills knowledge expertise related to the application field - DOMAIN-RELEVANT SKILLS, which specifically includes relevant basic knowledge, product knowledge, process or process experience, technical essence, special skills, etc.; second, the skills and skills related to the production of creativity itself - CREATIVITYRELVANT SKILLS, that is, creative thinking ability, which specifically includes 3 categories of skills: cognitive ability that can break through the convention of things or problems, heuristic and exploratory problem solving methods, and work methods that are conducive to creativity; third, the related task motivation - TASK MOTIVATION, that is, the individual's belief and desire to complete the corresponding task.

In 2016, Amabile \& Pratt [13] summarized the research and development based on the component model of creativity in the past 30 years, and updated and defined the component structure model. This update focuses more on the interpretation of the mental process related to creativity at the individual level. It also highlights the important influence of the work environment on the individual's mental process, and introduces four new constructs into the model: the sense of progress in creativity, meaning of work, emotion, and external incentives with synergy. People can be driven to complete a task by the interest, enjoyment, satisfaction and challenge of the work themselves, or they can be driven to complete a task by external pressure, such as a deadline, or some positive motivating factors, such as motivation and recognition, or some internal and external factors. In terms of the principle of intrinsic motivation of creativity, the original model theory believes that the most creative motivation of people is mainly interest, enjoyment, satisfaction and challenge of the work itself, rather than external pressure or motivational factors. The new model theory recognizes that external incentives are first divided into two categories, information-based external incentives and controlled external incentives: Information-based external incentives refer to not undermining the individual's right to make decisions, but to provide more information support and feedback, confirm the improvement of the individual's ability, recognize the value of the individual's work, and try not to give mandatory target control; controlled external incentives are to give individuals goals and requirements, rather than letting individuals decide more autonomously what to do and what their goals are. Individuals will feel controlled and demanded.

\subsection{The Evolutionary Model of Creativity}

The evolutionary model of creativity proposed by Campbell [15] believes that creativity is not a mysterious process that only outstanding people can show. He believes that creativity requires a lot of trial and error process and hard work. People must come up with various solutions to solve problems. For this, they need to use various methods, based on personal knowledge, skills, experience and background in the process of selecting solutions. Simonton [16] further referred to the theory of biological evolution and proposed that the process of creativity is the process of creativity and selective retention of creativity. Originality represents the generation of new ideas, while selective retention is based on the practical benefits of new ideas. Since novelty is regarded as the difference between creative work and higher than practical work, Simonton puts the theoretical emphasis on the creation of originality. He believes that the creation of originality is not blind or random, and that existing knowledge elements can be combined into new originality. The selection is initially made in the minds of creative people, who use the corresponding indicators of practicality, appropriateness, and novelty to measure ideas. At a certain point in time, the creativity is shared by 
everyone, and then further originality and creative choices are produced.

\subsection{The Investment Model of Creativity}

Sternberg \& Lubart [17] borrowed from the concept of investment theory and proposed a creativity model that regards creativity as the use of one's six psychological resources for creative investment, namely the creativity investment model theory. This model believes that people with creativity have common characteristics, which can be summarized as "buy low and sell high" in similar investment fields; people will invest their own psychological resources into different new thoughts and new ideas based on the potential profitability they think, in order to obtain the greatest return on creativity. The six kinds of psychological resources include: intelligence, knowledge, thinking style, personality, motivation, and environment. They are integrated and organically constitute creativity and creative products, outputs and results in different fields. Because these six psychological resources come from different dimensions, creativity is also regarded as having a multi-dimensional structure.

\subsection{The Interaction Model of Creativity}

Woodman et al. [18], [19] proposed an interactive model of creativity. They believe that creativity is a complex interaction between people and situations, affected by personal past experience and current situation; at the individual level, people's cognitive ability, style, and non-cognitive factors are all related to creativity; environmental and social influences can also promote or inhibit creativity.

\subsection{The Dynamic Model of Creativity}

The dynamic model of individual creativity proposed by Ford [20] believes that an individual's creative activity is a combination of the individual's knowledge, ability and motivation, as well as the construction of meaning. For individuals, creativity and habit are two opposing behavior choices. Generally speaking, as long as the habitual behavior is attractive, even if the environment helps creativity, people will still choose the habit.

\section{FACTORS AFFECTING EMPLOYEE CREATIVITY}

According to the summary and collation of existing creativity-related research, it can be found that more and more researchers are focusing on the research of employee creativity. In the early days, more Western developed countries started related research. Recently, more and more developing countries, including China, have gradually begun related exploration work. Research has found that employee creativity is affected by many different factors. In actual research, the relevant factors can be roughly divided into type similarities: leadership-related factors, organizational-level factors, individual-related factors, environmentrelated factors, and task-related factors.

\subsection{Research on the Influence of Leadership-related Factors on Employee Creativity}

According to the research on the relationship between employee creativity and leadership so far, it has been shown that leadership-related factors, such as leadership, may have an important impact on employee creativity [21]. The related research on the variables of leadership factors mainly include: the effect of leadership type or leadership style on employee creativity, the effect of the quality of the relationship between leadership and employees on employee creativity, and the effect of other aspects of leadership or specific behaviors on employee creativity. For example, transformational leadership can positively affect employees' innovation ability [22], there is a positive correlation between moral leadership and employee creative behavior [23], and authoritarian leadership has a negative impact on employee creativity [24].

\subsection{Research on the Relationship Between Organizational-level Factors and Employee Creativity}

Organizations formulate strategies, design organizational structures, define and formulate key policies, and communicate and implement values. Amabile \& Pratt [13] in the model theory of creativity more focused and detailed description of the organization's work environment, there are many catalyst factors that can promote work progress, which can enhance personal creativity and performance, and continue to improve creativity, self-efficacy and intrinsic motivation [25]. Organizational knowledge sharing and learning 
atmosphere, work system and human resource management have a significant impact on employee creativity. For example: knowledge sharing and personal-organizational fit have a positive impact on individual creativity [26]; organizational learning culture has a positive impact on employee creativity [27]. Organizational-level incentives, commitments, corporate social responsibility, organizational work and communication atmosphere also have a significant impact on individual employees' creativity, for example: organizational innovation atmosphere, physical work environment, and encouragement to work have a positive effect on the improvement of employee creativity [28].

\subsection{The Relationship Between Employee Individual-related Factors and Employee Creativity}

In the research related to employee creativity, the main factors related to individuals are: creativity self-efficacy, intrinsic motivation, psychological capital, innovative personality, knowledge sharing or hidden behaviors, etc. Specific research examples include: creative selfefficacy mediates the positive correlation between leadership creative expectations and employee creativity [29], feedback seeking behavior mediates the relationship between creative self-efficacy and employee creativity. This moderating effect is adjusted by the focus of promotion [30]. Psychological capital is positively correlated with employee creativity. Optimism and hope can improve employees' self-efficacy and flexibility, which is beneficial to employees' creativity [31] and employee competence. [32] There is also a direct or indirect correlation with employee creativity.

\subsection{Research on Environment-related Factors}

In the research related to employee creativity, the main environmental factors are: working environment, uncivilized workplace, etc. Specific research examples include: in the relationship between transformational leadership and employee creativity, employee creativity self-efficacy plays a mediating role, while the physical working environment plays a moderating role [33]; uncivilized behavior in the workplace is negatively correlated with employee creativity [34].

\subsection{Factors Related to Work Tasks}

Factors related to work tasks can also affect employee creativity. For example, challenging work needs are positively correlated with work engagement and employee creativity, and obstructive work needs are negatively correlated with job engagement and employee creativity [35]. Through the refinement of employee information, individual task conflicts are positively correlated with individual creativity [36].

\section{RESEARCH STATUS}

The research on creativity originated from research in the field of psychology. In the early stages of development, it mainly focuses on exploring the influence of personality traits, intrinsic ability and other individual traits on creativity from the perspective of individuals [37]. The main characteristic factors included are: creativity self-efficacy, intrinsic motivation, psychological capital, personality traits, education and quality background, etc.

Related research mainly has two key research directions: some researchers take the personality characteristics as the main orientation to analyze the personality characteristics of creativity-related talents, with the purpose of finding out the personality characteristics of highly creative talents that are different from ordinary people; the other part of the researchers takes the cognitive process as the research orientation, focusing on the research of the operating and processing mechanism of creative thinking closely related to creativity, in order to find those cognitive processing methods and processes that can cause and produce novel and effective solutions or perform tasks. Creativity research from the individual perspective allows people to understand the psychological and physical characteristics that have an impact on individual creativity, and can guide recruitment practices and select highly creative talents in work practice [38].

Creativity-related personality traits and intrinsic abilities usually have greater stability. Although cognitive processing ability can develop, it takes a long time. The direct intervention of the organization has very limited impact on them; comparatively speaking, it is relatively easy to implement management measures to influence and change the external context of employees' creativity, and changes in context can have a more direct and obvious impact on employee behavior. Therefore, 
after studying the factors of individual characteristics, researchers began to explore the effect of external situational factors on employees' creativity.

\section{RESEARCH EXPECTATIONS}

Most of the existing research on employee creativity is based on the social, cultural and economic background of the Western context, and the results may not be completely applicable to the Chinese context: The traditional background of Confucian culture in Eastern societies, including China, emphasizes the control and influence exerted by the external environment on individuals, emphasizing collectivism, pragmatism, and obedience, etc. While in Western cultural traditions, individuals are more controlled by themselves, advocating more freedom, individuality, and expectations, and tending to individualism and expressionism. Differences in these social and cultural factors can lead to different results in creativity [39], [40]. When Rice [41] conducted research on non-Western Egypt, he found that cultural values have different effects on creativity. The mutual care in Egyptian cultural characteristics can promote creativity, while compliance has a negative impact on creativity; Wang Guobao's [42] research confirms that the collectivism and face tendencies in Chinese cultural factors will have more influence on the creativity of employees. In the future, researchers in the Chinese context should continue the academic community's emphasis on employee creativity, focus on the needs of Chinese companies in the Chinese context and the status quo, and carry out in-depth research on the specific mechanisms of what factors and how the creativity of Chinese employees is affected.

\section{CONCLUSION}

Employee creativity is the prelude and foundation of innovation, and related theoretical research needs to be expanded and extended. The research results in the Chinese context should aim to support the practical management of creativity, and further explore the potential direct and indirect factors that affect the creativity of employees, as well as the mutual influence of the factors, and are affected by the national conditions and cultural characteristics, analyze its influence mechanism, and clarify its boundary conditions. Finally, the results need to be able to provide theoretical foundation and practical guidance for enterprise organizations to achieve creativity enhancement and innovation performance.

\section{AUTHORS' CONTRIBUTIONS} Guo.

This paper is independently completed by Feng

\section{REFERENCES}

[1] Zhou, J., Feedback valence, feedback style, task autonomy, and achievement orientation: Interactive effects on creative performance. Journal of Applied Psychology, 1998. 83(2): p. 261-276.

[2] Ding, G., et al., Enterprise social networking usage as a moderator of the relationship between work stressors and employee creativity: A multilevel study. Information \& Management, 2019. 56(8): p. 103165.

[3] Dong, Y.T., et al., Enhancing employee creativity via individual skill development and team knowledge sharing: Influences of dualfocused transformational leadership. Journal of Organizational Behavior, 2017. 38(3): p. 439-458.

[4] Cai, W., et al., Psychological capital and self - reported employee creativity: The moderating role of supervisor support and job characteristics. Creativity and Innovation Management, 2019. 28(1): p. 30-41.

[5] Shalley, C.E. and L.L. Gilson, What leaders need to know: A review of social and contextual factors that can foster or hinder creativity. Leadership Quarterly, 2004. 15(1): p. 33-53.

[6] Rogers, C.R., Toward A Theory of Creativity. ETC: A Review of General Semantics, 1954. 11(4): p. 249-260.

[7] Busse, T.V. and R.S. Mansfield, Theories of the creative process: A review and a perspective. The Journal of Creative Behavior, 1980.

[8] Guilford, J.P., Creativity. American Psychologist, 1950. 5(9): p. 444-454.

[9] Amabile, T.M., Social-Psychology of Creativity - A Consensual Assessment Technique. Journal of Personality and Social Psychology, 1982. 43(5): p. 997-1013. 
[10] Zhou, J. and J.M. George, When job dissatisfaction leads to creativity: Encouraging the expression of voice. Academy of Management Journal, 2001. 44(4): p. 682-696.

[11] Daft, R.L., Dual-Core Model of Organizational Innovation. Academy of Management Journal, 1978. 21(2): p. 193-210.

[12] Amabile, T.M., A Model of Creativity and Innovation in Organizations. Research in Organizational Behavior, 1988. 10: p. 123-167.

[13] Amabile, T.M. and M.G. Pratt, The dynamic componential model of creativity and innovation in organizations: Making progress, making meaning. Research in Organizational Behavior, 2016. 36: p. 157-183.

[14] Amabile, T.M., The Social-Psychology of Creativity - A Componential Conceptualization. Journal of Personality and Social Psychology, 1983. 45(2): p. 357-376.

[15] Campbell, D.T., Blind variation and selective retentions in creative thought as in other knowledge processes. Psychological review, 1960. 67(6): p. 380.

[16] Simonton, D.K., Origins of genius: Darwinian perspectives on creativity. 1999: Oxford University Press.

[17] Sternberg, R.J. and T.I. Lubart, Defying the crowd: Cultivating creativity in a culture of conformity. null. Vol. null. 1995. null.

[18] Woodman, R.W. and L.F. Schoenfeldt, An interactionist model of creative behavior. The Journal of Creative Behavior, 1990.

[19] Woodman, R.W., J.E. Sawyer, and R.W. Griffin, Toward A Theroy of Organizational Creativity. Academy of Management Review, 1993. 18(2): p. 293-321.

[20] Ford, C.M., Theory of individual creative action in multiple social domains. Academy of Management Review, 1996. 21(4): p. 11121142.

[21] Tierney, P., S.M. Farmer, and G.B. Graen, An examination of leadership and employee creativity: The relevance of traits and relationships. Personnel Psychology, 1999. 52(3): p. 591-620.

[22] Tse, H.H.M., M.L. To, and W.C.K. Chiu, When and why does transformational leadership influence employee creativity? The roles of personal control and creative personality. Human Resource Management, 2018. 57(1): p. 145-157.

[23] Duan, S.H., Z.Y. Liu, and H.S. Che, Mediating Influences of Ethical Leadership on Employee Creativity. Social Behavior and Personality, 2018. 46(2): p. 323-338.

[24] Guo, L., et al., Authoritarian leadership and employee creativity: The moderating role of psychological capital and the mediating role of fear and defensive silence. Journal of Business Research, 2018. 92: p. 219-230.

[25] Binnewies, C. and S.C. Woernlein, What makes a creative day? A diary study on the interplay between affect, job stressors, and job control. Journal of Organizational Behavior, 2011. 32(4): p. 589-607.

[26] Ouakouak, M.L. and N. Ouedraogo, Antecedents of Employee Creativity and Organisational Innovation: An Empirical Study. International Journal of Innovation Management, 2017. 21(7): p. 26.

[27] Khurosani, A., Transformational Leadership, Employee Creativity and Organizational Innovation, The Intervening Role of Organizational Learning Culture. Advanced Science Letters, 2018. 24(4): p. 2557-2560.

[28] Chaubey, A. and C.K. Sahoo, Honing of employee creativity in Indian automobile industry. Journal of Management Development, 2018. 37(7): p. 552-572.

[29] Jiang, W. and Q.X. Gu, Leader creativity expectations motivate employee creativity: a moderated mediation examination. International Journal of Human Resource Management, 2017. 28(5): p. 724-749.

[30] Chen, Y. and L. Zhang, Be creative as proactive? The impact of creative self-efficacy on employee creativity: A proactive perspective. Current Psychology, 2019. 38(2): p. 589-598.

[31] Yu, X.F., et al., The role of psychological capital in employee creativity. Career Development International, 2019. 24(5): p. 420-437.

[32] Chang, C.P. and P.C. Hsu, The correlation between employee information literacy and 
employee creativity. Quality \& Quantity, 2015. 49(1): p. 221-234.

[33] Chaubey, A., C.K. Sahoo, and N. Khatri, Relationship of transformational leadership with employee creativity and organizational innovation A study of mediating and moderating influences. Journal of Strategy and Management, 2019. 12(1): p. 61-82.

[34] Zhan, X.J., Z.C. Li, and W.H. Luo, An identification-based model of workplace incivility and employee creativity: evidence from China. Asia Pacific Journal of Human Resources, 2019. 57(4): p. 528-552.

[35] Li, X. and C. Li, Not All Job Demands Are Equal: Differentiating the Effects of Challenge and Hindrance Job Demands on Employee Creativity, in Proceedings of the 2016 International Conference on Economy, Management and Education Technology, Z. Jiang and Y. Xue, Editors. 2016, Atlantis Press: Paris. p. 550-555.

[36] Li, C.R., C.X. Li, and C.J. Lin, The effect of individual task conflict on employee creativity: A moderated mediation model. Thinking Skills and Creativity, 2019. 31: p. 112-124.

[37] Gu Yuandong, Zhou Wenli, Peng Jisheng, Study on Influencing Mechanism of Perceived Organizational Support on R \& D Staffs' Innovative Behaviors [J]. Management Sciences in China, 2014 (01): p.109-119. (in Chinese)

[38] Liu Yun, Shi Jintao, The Research Logic of Employee Creativity [J]. Modern Management Science, 2009 (01): p.99-101. (in Chinese)

[39] Runco, M., Personal creativity and culture, in Creativity: When east meets west. 2004. p. 921.

[40] Leung, K., A. Au, and B.W. Leung, Creativity and innovation: East-West comparisons with an emphasis on Chinese societies, in Creativity: When east meets west. 2004. p. 113-135.

[41] Rice, G., Individual values, organizational context, and self-perceptions of employee creativity: Evidence from Egyptian organizations. Journal of Business Research, 2006. 59(2): p. 233-241.
[42] Wang Guobao, Research on the Impact of Chinese Cultural Factors on Knowledge Sharing and Employee Creativity [D]. Zhejiang University, 2010. (in Chinese) 